\title{
Based on GSM Wireless Fire Alarm System
}

\author{
Jianli Zheng \\ Donghua University \\ Institute of InformationScience and \\ TechnologyShanghai Songjiang201620
}

\author{
Yaping Tu \\ Donghua University \\ Institute of Information Science \\ and Technology \\ Shanghai Songjiang201620
}

\begin{abstract}
The smart home system can be defined as a process or a system.Compared with ordinary household,the smart home not only has the traditional residential function, it also provides high grade safety and comfortable delightful family living space.This system is based on the core device of the STC89C52 MCU and MQ-2 smoke sensor,in the form of short message to implement the fire alarm and remote control, home security supervision. The system uses temperature sensor, infrared sensor, and gas sensors to ensure house's security.Once abnormality occurred,it will send a message as alarm to the house-owner.And by the remote control of turning on the light and sound recording to simulate the effect of someone in the house, the thief will give up stealing.
\end{abstract}

\section{Keywords}

Smart-home:Fireproofing and security system;MCU.

\section{INTRODUCTION}

With the rapid development of science and technology,the living standard of people also improves constantly.However the hidden danger of fire follows the huge progress of science and technology.Accompanied with the big progress of the science technology, fire alarm system must be keeping a faster development.Researches on smoke detection method and the development of smoke alarm become an important topic in the field of sensor technology development.

Smoke alarm system has turned up in China in the early 1970 s. The system presents a variety of types, but it's mainly in the introduction of foreign advanced sensor technology and advanced production technology.In recent years, the system on the selectivity on sensors and stability has great
progress.However expensive costs on smart home makes it difficult for public to obtain. This paper provides a kind of low cost, reliable performance, easy installing, less investment of intelligent alarm system.It is based on STC89C52 MCU as the central processor,and the hardware circuit redesigned and improved to make its functions more complete.

\section{PRINCIPLE OF SYSTEM DESIGN}

\subsection{Ideas of design}

At present,the most prevailing home alarm system in the market is achieved by telephone dial-up alarm function to the outside world.However, duo to the fixed telephone wiring closet are mostly concentrated in the corridor of residential building, if the thief opens the wiring closet and damages the telephone line before he breaks into, alarm system will lost the function of the alarm to the outside world.Aiming at this problem mentioned above, GSM mobile communication technology is introduced into the design of the system so that it can completely avoid the possibility of destruction.And it functions more complete, greatly increasing the reliability and security of the alarm at the same time.

\subsection{System block diagram}

MCU and GSM SMS module is the heart of Home intelligent fire alarm system. The system configuration block diagram is shown in fig 1 .The system includes a clock circuit, security information acquisition and processing module, the fire information acquisition and processing module, temperature humidity detection module, GSM mobile communication module, STC89C52 MCU, control module and display module.

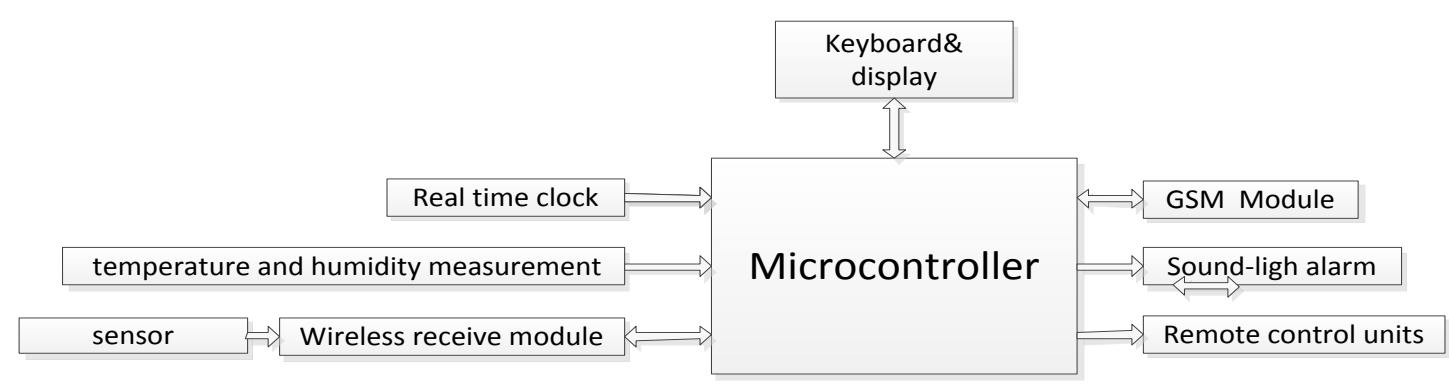

Fig 1:System configuration block diagram

\section{SYSTEM FUNCTION MODULE}

\subsection{Minimum control system of MCU}

The minimum control system of MCU is shown in fig 2.It includes a micro-controller, reset circuit and clock circuit.STC89C52 MCU working voltage ranges from $4 \mathrm{~V}$ to 5.5 V.Usually it is given $5 \mathrm{~V}$ DC power supply. The 40 pin of
MCU connects the positive $5 \mathrm{~V}$ while 20pin connects VSS power supply.Reset circuit is to ensure micro-controller work at starting state to accomplish start process of MCU.Reset signal generates when MCU is given power supply and MCU is on the start working condition. 


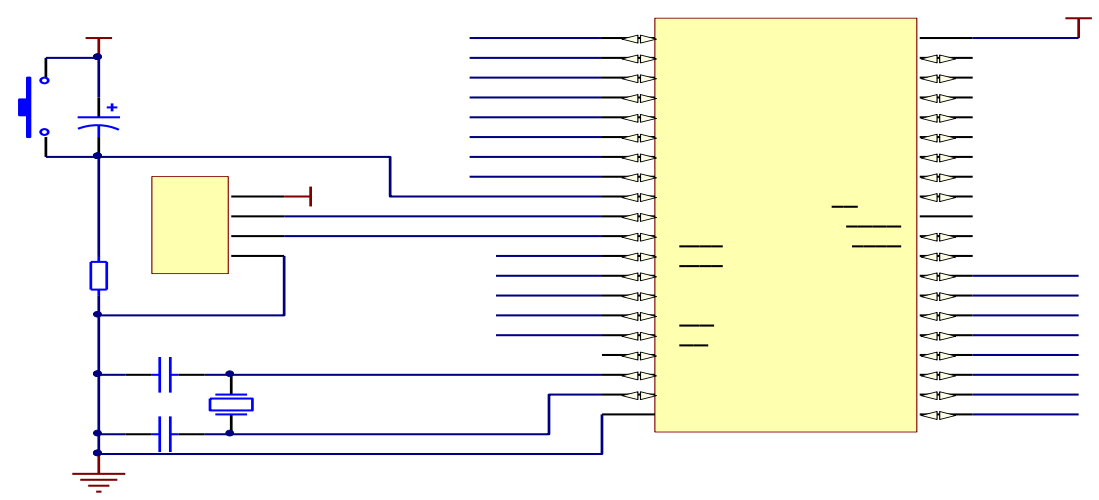

Fig 2:The minimum control system of MCU

\subsection{AD sampling detection}

MQ-2 sensor is used to detect the combustible gas.After ADC0832's acquisition, the system can get all kinds of smoke concentration under voltage value. Thus the system can set the ideal strength of smoke alarm value before it's put to use.

\subsection{Displaymodule}

The display module is necessary as a man-machine interaction bridge.Display module can display real-time temperature and gas density, and in the manual setting of smoke alarm value and temperature alarm value.And the owner can set alarm value of temperature and gas density by their own favor using the man-machine display module.Furthermore,the owner can set the telephone number which the fire-alarm system sends messages to.

\subsection{Sound alarm circuit}

By using a pull-up transistor connected with base of audion and the micro-controller P3.6 port,the MCU can control buzzer alarm. When the temperature exceeds limit or combustible gas concentration exceeds ceiling, buzzer alarms and message sent.The owner needs to cancel the buzzer alarm through button control circuit.

\subsection{Button control circuit}

P1.0, P1.1, P1.2 and P1.3 of MCU make up a $4 * 4$ matrix keyboard.Matrix keyboard is set up in order to set the telephone number which owner sends message to.And S5,S9 in matrix keyboard can make the system in a state of setting temperature and gas concentration.S13 and S17 can change the value respectively plus 1 and minus 1 .That is to avoid user to remove the MCU and load the new program from computer,increasing the usability of the system. The button control circuit is shown in fig 3 .

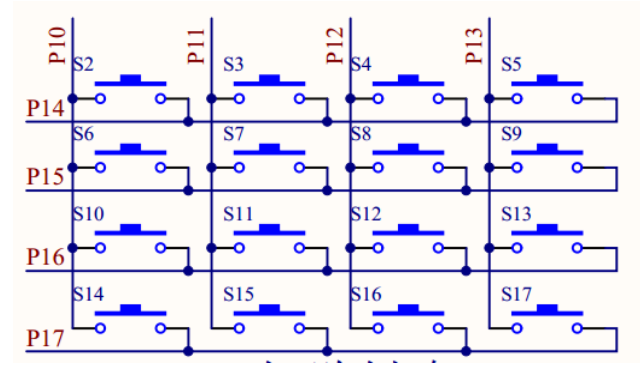

Fig 3: Button control circuit

\subsection{Temperature acquisition circuit}

This system uses power supply of DS18B20 instead of parasitic power supply mode to ensure the effective DS18B20 clock to provide enough stable current.The pin 1,pin2 and pin3 of DS18B20 respectively connect the ground,signal line and power.To get enough stable current supply,the system contains a pull-up resistors with PIN 2.3 of MCU. So the temperature sensor can detect the temperature of the surroundings.

\subsection{Audio record circuit design}

When people on vacation or other reasons away from home,the thief may get the chance to break into.So imaging if there is a voice chip prior to record some sound in daily life like washing, cooking, the voice of the people dialogue or a piece of music.In that way, the house-owner can sent message to control this chip to play the those sound at their convenience.That takes a feeling of someone at home,letting the thief take initiative to give up stealing.

\subsection{Human body induction module}

As shown in fig 4 is human body induction circuit.D3 is protection indicator while D2 is sensor signal indicator.If there is the human body in its sensing range of activities, its output will always keep a high level.Its output won't go down until the people left.
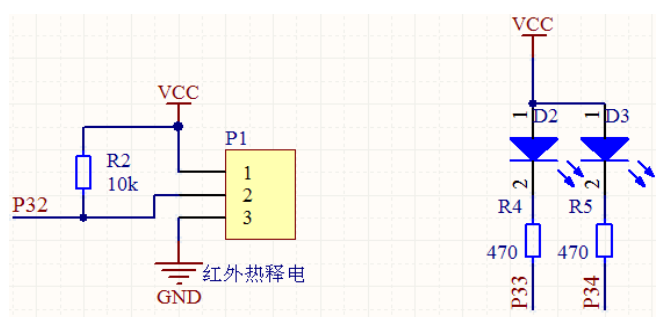

Fig 4:Audio record circuit design

\section{SYSTEM SOFTWARE DESIGN}

While the hardware plays an important role in the firealarmsystem,the system also needs software's support. The mainprogram flow is shown in fig 5 . 


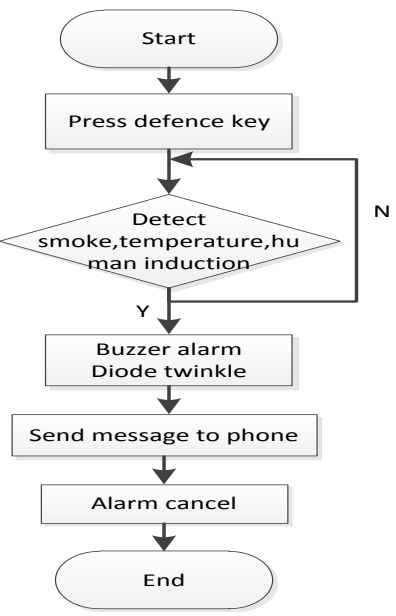

The function of this main program's function is: when the combustible gas density or the temperature is out of the value set before,it indicates there is fire.And when pyroelectric infrared sensor detects someone's approaching,it indicates there is someone breaking into.Those signals will be processed by the inner program in MCU,and then plays the alarming sound and sends the message to the owner.So the owner can deal with the emergency situation and reset the MCU.The MCU get into the state of continuous work in detecting the gas, temperature and someone breaking into after the owner manages the emergency.

The simulation result is shown in fig 6 below.It's running in proteus.After ensuring theq feasibility of this detected system,PCB board can be welded to put into practical application.

Fig 5: The main program flow chart

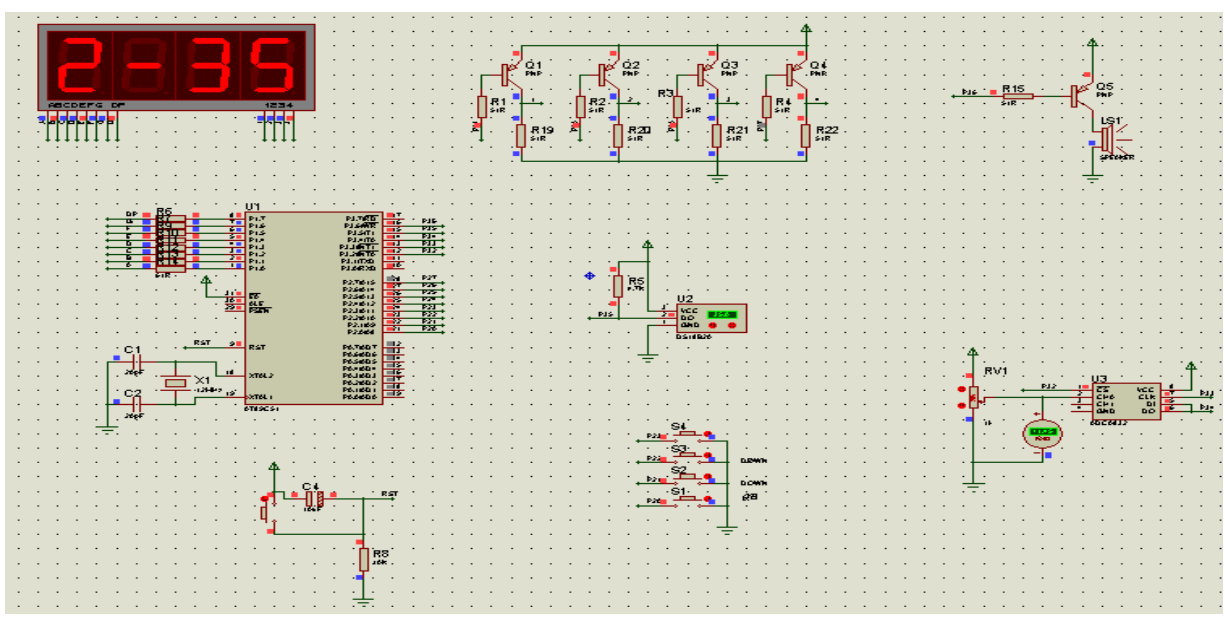

Fig 6: simulation of the system on working state

\section{TESTING AND ANALYSIS}

After completion of the whole system design,the system must be carried on the debugging operation, excluding bugs both in hardware and software. And the system should be checked in the reliability and stability at the same time to meet the requirement of the system. The debugging of this system mainly contains two steps:single chip microcomputer system debugging and the whole control system running debugging.Combining with software system test,using hardware platform for functional testing,the whole system can be tested in running normally or abnormally. The test mainly contains the pyroelectric infrared sensor, keyboard input, smoke sensor, digital display as well as each unit of the system functioning in right condition.

\section{CONCLUSION}

On the basis of in-depth study of fire alarm system,with comprehensive comparison of technical characteristics of similar products at home and abroad,this paper reasonably designs the scheme of the system. The system designs and validates a low-cost scheme of smart home,and also realize monitoring the accident of fire and alarming. And the system presents a extensibility of secondary development.The advantages of the system can be listed as simple operation, low cost, convenient installation, easy popularization and high reliability.That suits for common family security detection.

\section{REFERENCES}

[1] Zheng Feng. Typical module development of 51 singlechip microcomputer application system [M]. Beijing: China railway publishing house, 2013.11.

[2] Aijun Xu. Keil C51 application programming in a highlevel language and practice [M]. Beijing: Electronic industry press, 2013.12 .

[3] Huaguang Kang. Electronic technology foundation.[M]. Beijing: Higher education press, 2006.1.

[4] Xiaoping Gao. China's present situation and development trend of intelligent household [J]. Journal of low voltage apparatus, 2005 (4) : 18 to 21

[5] Chongming Xie. GSM car alarm system design [J]. Journal of safety science and technology, 2008, (5) : 3133.

[6] Jinquan Zhang. A new type of civil fire anti-theft alarm development [J]. Journal of Yanshan University, 2000, (3).

[7] Honghai Fu. Single chip microcomputer application in the security alarm system $[\mathrm{J}]$. Journal of safety science and technology, 2009 (3) : 25.

[8] XinSun,Shan'an Zhu.Intelligent monitoring anti-theft alarm system [J]. Journal of design and application of electronic technology, 2012 (2) : 28 to 30. 